\title{
Effects of silver nanoparticles added into polyurea coating on sulfate-reducing bacteria activity and electrochemical properties; an environmental nano-biotechnology investigation
}

\author{
Hassan Karimi-Maleh $^{\text {a,b,c, }}$, Seyed Jafar Mousavi ${ }^{\text {b }}$, Majid Mahdavian ${ }^{\text {b, }{ }^{* *},}$, Mouj Khaleghi ${ }^{\text {d }}$, \\ Sajjad Bordbar ${ }^{\mathrm{e}}$, Mehmet Lütfi Yola ${ }^{\mathrm{f}}$, Rozhin Darabi ${ }^{\mathrm{g}, * * * k}$, Mei Liu ${ }^{\mathrm{h}}$

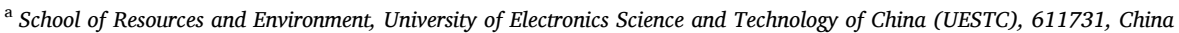 \\ ${ }^{\mathrm{b}}$ Department of Chemical Engineering and Energy, Quchan University of Technology, Quchan, Iran \\ ${ }^{c}$ Department of Chemistry, University of Johannesburg, P.O. Box 17011, Doornfontein Campus, Johannesburg, 2028, South Africa \\ ${ }^{\mathrm{d}}$ Department of biology, Faculty of Science, Shahid Bahonar University of Kerman, Kerman, Iran \\ ${ }^{\mathrm{e}}$ Department of Metals, Institute of Materials Science and Engineering, Graduate University of Advanced Technology, Kerman, Iran \\ ${ }^{\mathrm{f}}$ Hasan Kalyoncu University, Faculty of Health Sciences, Department of Nutrition and Dietetics, Gaziantep, Turkey \\ ${ }^{g}$ Department of Analytical Chemistry, Faculty of Chemistry, University of Kashan, Kashan, Islamic Republic of Iran \\ ${ }^{\mathrm{h}}$ School of Petrochemical Engineering, Liaoning Petrochemical University, Fushun, 113001, Liaoning, China
}

\section{A R T I C L E I N F O}

\section{Keywords:}

Polyurea

$\mathrm{Ag}$ nanoparticles

Antibacterial effect

Corrosion

\begin{abstract}
A B S T R A C T
In the present work, Ag nanoparticles were added to polyurea coating in order to improve its antibacterial and electrochemical properties in sulfide-reducing bacteria-containing media. To this end, Ag nano-powder was mixed with two component polyuria, and then the antibacterial behavior of the nanocomposite coating was studied in sulfate-reducing bacteria (SRB)-containing medium. The results revealed the inhibitory effects of nanocomposite coating on the formation of SRB biofilms on the samples. Moreover, the SRB population decreased in contact with the Ag nanoparticles-mixed coating over 7 days. Investigation of the growth and activity of the bacteria represented the effective antibacterial properties of $\mathrm{Ag}$ nanoparticles in the polyurea matrix. Furthermore, EIS (electrochemical impedance spectroscopy) measurements indicated that the corrosion properties of the nanocomposite coating improved considerably over 7 days. The coating resistance increased 2 times by adding Ag nanoparticles after 1 day and 3.3 times after 7 days. In accordance with the same results, the charge transfer resistance increased 1.5 times and 1.1 times by adding Ag nanoparticles after 1 day and 7 days, respectively. The improvement in the protective properties of the nanocomposite coating are reflected in the increase in both film and charge transfer resistance.
\end{abstract}

\section{Introduction}

Microorganisms are known as one the most effective parameters on the corrosion behavior of industrial equipment. However, one type of corrosion that can produce unexpected problems, premature failures, and costly repairs is microbiologically influenced corrosion (MIC). MIC is not a form of corrosion; rather, it is a process that can influence and even initiate corrosion and accelerate most forms of it. Pitting and fouling in a heat exchanger tube (Sharma, 2014) and failure of an API 5L X52 trunkline (Elshawesh et al., 2008) have been reported to have occurred due to microbiological-influenced corrosion. Moreover, the MIC risk in a pipeline transmission network has been previously assessed (Kaduková et al., 2014).

In modern times, a wide range of coating and paints are formulated with antibacterials and/or biocides or special chemicals which control the growth of microorganisms (Ma, 2019; Bushnak et al., 2010). In addition, polymers with unique physical and chemical properties are very motivating in the industrial field (Tan and Blackwood, 2003; Mallon, 2003; Khodadadi et al., 2019). Therefore, polymer-based composites with mechanical strength, adhesive property, and the highest

\footnotetext{
* Corresponding author. School of Resources and Environment, University of Electronics Science and Technology of China (UESTC), 611731, China.

** Corresponding author. Department of Chemical Engineering and Energy, Quchan University of Technology, Quchan, Iran.

$* * *$ Corresponding author.

E-mail addresses: hassan@uestc.edu.cn (H. Karimi-Maleh), m.mahdavian@qiet.ac.ir (M. Mahdavian), darabirozhin@yahoo.com (R. Darabi).
} 


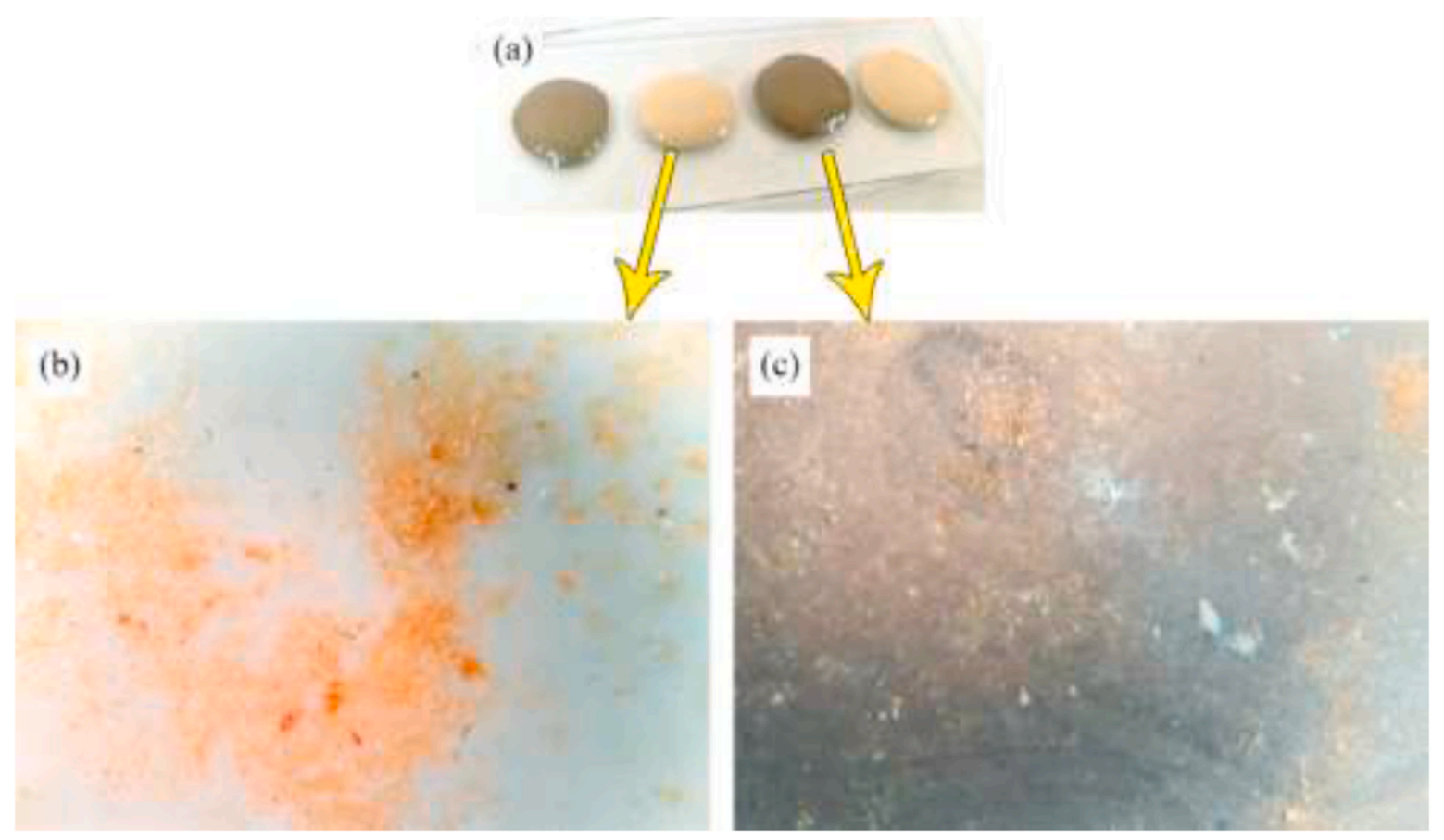

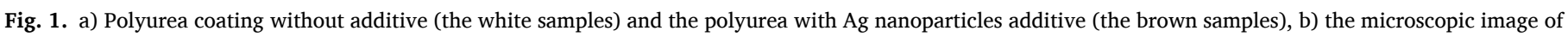

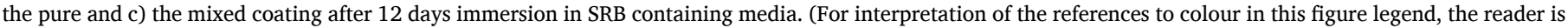
referred to the Web version of this article.)

resistance are an important choice in corrosion investigations (Mansfeld, 1995; Jafari et al., 2014; Shabani-Nooshabadi et al., 2014, 2015; Ghoreishi et al., 2012).

Nanomaterials have created a new approach to most science trends, especially engineering (Ahmadi et al., 2020; Cha-Umpong et al., 2019; Kumar et al., 2018; Dehhaghi et al., 2019; Hosseinzadeh-Bandbafha et al., 2019; Karaman et al., 2020; Karimi-Maleh et al., 2014, 2021a, 2021b, 2021c; Alavi-Tabari et al., 2018). Focusing on materials in the nanoscale has made it possible to transform scientific principles and create access to better conditions in most sciences (Cha-umpong et al., 2021; Mohammad et al., 2020; Razmjou et al., 2019; Neeraj et al., 2016; Khalife et al., 2017; Mirzajanzadeh et al., 2015; Özcan et al., 2020; Akça et al., 2021; Karimi et al., 2020; Arzaghi et al., 2021). Meanwhile, metal-based nanoparticles, particularly Ag nanoparticles, have played a very important role in this regard (Kumar et al., 2010; Saravanan et al., 2016, 2020; Karimi-Maleh et al., 2020). Research into novel silver-based materials in the last years has reemerged as a very active field owing to their promising antibacterial activity against several microorganisms (Pour and Ghaemy, 2014; Sekhavat Pour and Ghaemy, 2014; Shi et al., 2008; Huang et al., 2011; Chen and Mao, 2007; Mirmohseni and Zavareh, 2010; Al-Turaif, 2010). These results are particularly interesting and encouraging, because these materials present strong antibacterial effects.

It has been previously reported that $\mathrm{Ag}$ nanoparticles coating can significantly improve the antibacterial activity and bacterial adhesion ability of the polyetheretherketone (PEEK) produced through magnetron sputtering (Liu et al., 2017). The effect of Ag-based compounds on the bio-corrosion, antibacterial property, and cell biocompatibility in $\mathrm{Ti}-\mathrm{Ag}$ alloys has also been investigated. It has been demonstrated that Ag nanoparticle precipitates have a significant influence on the antibacterial properties of the alloy (Chen et al., 2017). Furthermore, another study investigated the antibacterial properties of $\mathrm{Ag}$ nanoparticles by embedding them into an amorphous carbon (a-C) matrix. The Ag/a-C nanocomposite coatings revealed an outstanding antibacterial activity promoting a total reduction in biofilm formation (Manninen et al., 2016). Moreover, silver/waterborne polyurethane-acrylate
(Ag/WPUA) coating was investigated; antibacterial tests revealed a reduction in bacterial which led to excellent antibacterial activity (Zhang et al., 2018). The goal of the current study is to investigate the effects of adding Ag nanoparticles to polyurea coating in order to improve its antibacterial and electrochemical properties in the presence of sulfide-reducing bacteria.

\section{Materials and methods}

\subsection{Isolation of the $S R B$}

The SRB used in this study, isolated from the bacterial library of Shahid Bahonar Kerman University, was extracted from seawater at Siri Island $\left(25.9143^{\circ} \mathrm{N}, 54.5273^{\circ} \mathrm{E}\right)$ in the Persian Gulf (Offshore Oil Company). Commonly used media were evaluated for SRB growth. Thioglycollic and ascorbic acids were used to increase their reducing power. The water sample was cultured in a sterile modified Postgate B culture medium (Ghazy et al., 2011).

The SRB were obtained by transferring the received seawater sample from the oil facilities into screw-cap vials containing Postgate medium B. The bacteria were incubated at $30^{\circ} \mathrm{C}$ for 7 days under anaerobic conditions. The modified Postgate $\mathrm{B}$ culture medium was composed of $\mathrm{KH}_{2} \mathrm{PO}_{4}(0.5 \mathrm{~g} / \mathrm{L}), \mathrm{NH}_{4} \mathrm{Cl}(1.0 \mathrm{~g} / \mathrm{L}), \mathrm{CaSO}_{4}(1.0 \mathrm{~g} / \mathrm{L}), \mathrm{MgSO}_{4} .7 \mathrm{H}_{2} \mathrm{O}(2.0$ $\mathrm{g} / \mathrm{L}), \mathrm{FeSO}_{4} \cdot 7 \mathrm{H}_{2} \mathrm{O}(0.5 \mathrm{~g} / \mathrm{L})$, sodium acetate $(3.5 \mathrm{~g} / \mathrm{L})$, sodium thioglycolate $(0.1 \mathrm{~g} / \mathrm{L})$, sodium ascorbate $(0.1 \mathrm{~g} / \mathrm{L})$, and yeast extract $(1.0 \mathrm{~g} /$ L) $(\mathrm{pH} 7.3)$.

\subsection{Antibacterial activity of coating on $S R B$}

The antibacterial activity of Ag nanoparticles was investigated on the isolated SRB consortium using the serial dilution test (Kahlmeter et al., 2006; Klančnik et al., 2010). To detect the MIC inhibitory effect of Ag nanoparticles, $1.0 \mathrm{~g}$ of $\mathrm{Ag}$ nanoparticles (Ag, 99.99\%, $20 \mathrm{~nm}$, US1038) was mixed with $200 \mathrm{~g}$ polyurea coating (Eurotaff Polyurea 300 cold) and put onto glass substrates. After 3 days (curing), the samples were exposed to the modified Postgate B culture medium plus $50 \mu \mathrm{l}(3.62 \times$ 
(a)

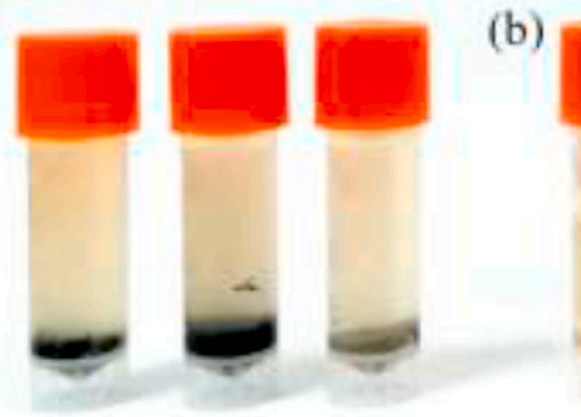

Control

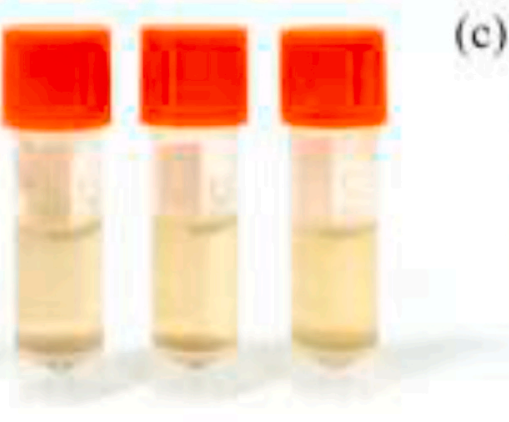

Polyurea (c)

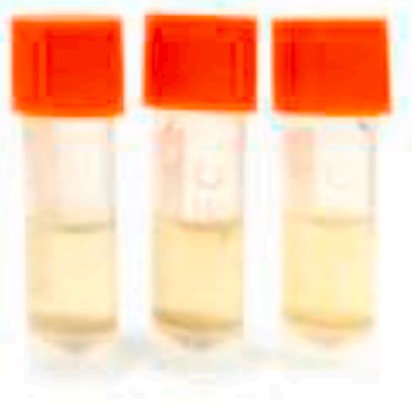

Polyurea + nano $\mathrm{Ag}$

Fig. 2. The modified Postgate B culture medium after 7 days for a) control sample, b) polyurea coating and c) polyurea coating mixed with Ag nanoparticles.
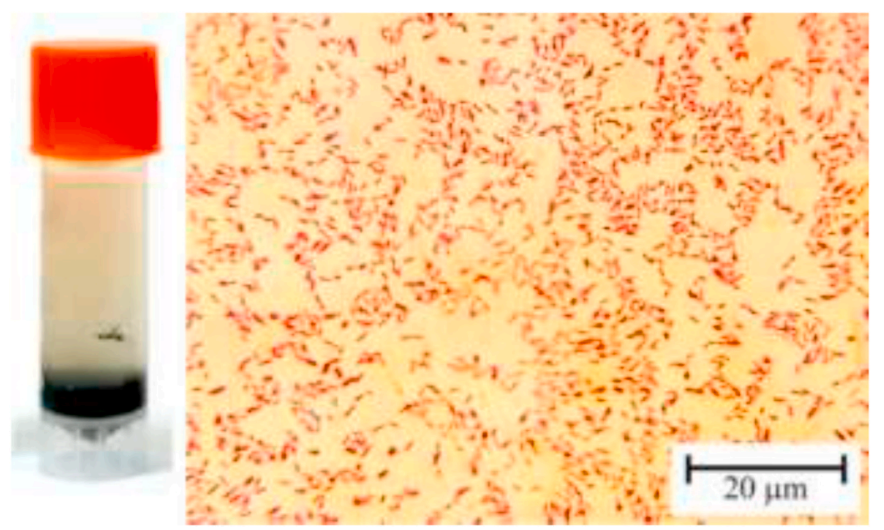

Fig. 3. Microscopic image of gram-negative, short, rod-shape SRB bacteria in control sample.

$10^{8} \mathrm{cell} / \mathrm{ml}$ ) of the SRB consortium, and the positive control (the culture medium with SRB) was prepared. Samples were incubated at $30^{\circ} \mathrm{C}$ for 8 days under anaerobic conditions. The bactericidal activity of the coated samples was evaluated by the culturing contents using the pour plate method.

\subsection{Electrochemical measurements}

To investigate the effects of adding Ag nanoparticles to polyurea coating on the electrochemical properties of the coating in immersion conditions, EIS measurements were taken at room temperature in the culture medium with SRB using a three electrode system including coated steel coupons as the working electrode, platinum wire as the counter electrode, and the saturated Calomel electrode (SCE) as the reference electrode. The area of the coupons exposed to the $\mathrm{NaCl}$ solution was $1 \mathrm{~cm}^{2}$. EIS measurement instruments included an Autolab 302N Potentiostat/Galvanostat with Nova V1.8 software (Metrohm, Switzerland). Impedance spectra of coupons in different immersion times of 1 day and 1 week were recorded in the $10^{-3}-10^{6} \mathrm{~Hz}$ frequency range with a sinusoidal alternating potential signal of $10 \mathrm{mV}$. EIS data was analyzed with ZSimpwin software.

\section{Results and discussion}

\subsection{Antibacterial effect}

To clarify the antibacterial effects of Ag nanoparticles on the polyuria matrix, the formation of biofilm on both samples (i.e. with and without nanoparticles) was investigated in the presence of SRB. Fig. 1a

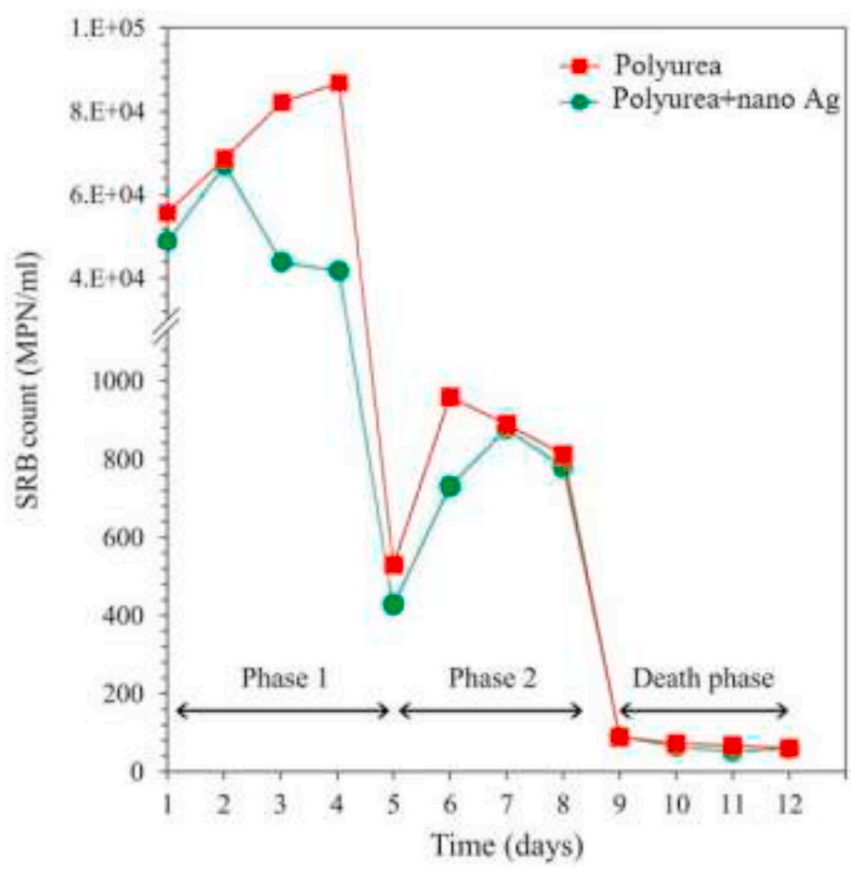

Fig. 4. The growth curve of bacterial population in the presence and absence of the $\mathrm{Ag}$ nanoparticles additive during 12 days.

shows an image of the polyurea coating without the additive (white samples) and the polyurea with $\mathrm{Ag}$ nanoparticles (brown samples). Fig. $1 \mathrm{~b}$ and $\mathrm{c}$ exhibit the microscopic images of the surfaces of the pure and mixed polyurea coating after 12 days immersion, respectively. The generated colonies of bacteria and biofilm are shown in Fig. 1b.

Despite Fig. 1b, the surface of the mixed sample (Fig. 1c) had no evidence of the presence of SRB colonies. The absence of biofilm on the surface of the mixed sample clarifies the antibacterial effects of the mixed sample of $\mathrm{Ag}$ nanoparticles in the polyurea matrix.

The presence of SRB in the modified Postgate B culture medium was proven by blackening, the smell of hydrogen sulfide gas, and the appearance of black sulfide sediments after 7 days, as shown in Fig. 2a.

Fig. $2 \mathrm{~b}$ and $\mathrm{c}$ shows the modified Postgate $\mathrm{B}$ culture medium in contact with polyurea coating and polyurea coating mixed with $\mathrm{Ag}$ nanoparticles after 7 days, respectively. As is clear in Fig. 2, the blackening did not happen in these media. Microscopic observations showed gram-negative, short, curved, rod-shaped bacteria (Fig. 3) that has been reported as SRB isolations in some publications (Ghazy et al., 2011; Javaherdashti, 2011).

As clearly indicated, the presence of Ag nanoparticles in the polyurea 
Table 1

Most probable number (MPN) and colony-forming unit (CFU) estimations after 12 days.

\begin{tabular}{lll}
\hline Coating & MPN/ml & CFU/ml \\
\hline Control & $>1100$ & $2.16 \times 10^{14}$ \\
Polyurea & 0.36 & $2 \times 10^{7}$ \\
Polyurea + Ag nanoparticles & 0.29 & $1 \times 10^{5}$ \\
\hline
\end{tabular}

coating led to control of the SRB activity and prevented the formation of SRB biofilms on the surface of the samples. The antibacterial effect of Ag nanoparticles is related to the strong interaction between $\mathrm{Ag}^{+}$and the thiol groups present in the enzymes involved in bacterial cell metabolism, thus causing cell death (Holtz et al., 2012).

\subsubsection{Bacterial activity and growth}

Fig. 4 represents the growth curve of the bacterial population over 12 days in the presence and absence of nanoparticles. Three different phases are exhibited in Fig. 4; phase 1 and 2 describe the activity of the bacteria, and the third phase shows bacteria death. The presence of two activity phases (1 and 2) is related to the diversity of species in the SRB consortium (AlAbbas et al., 2013; Bhola et al., 2014; Gayosso et al., 2004). Comparing the total count of SRB in the mediums of both coatings indicated the effects of $\mathrm{Ag}$ nanoparticles on SRB activity and growth. As shown in Fig. 4, the total count of the SRB in contact with the mixed sample decreased considerably.
Most probable number (MPN) and colony-forming unit (CFU) estimations are reported in Table 1 . The reported data once again clarifies the antibacterial effect of the $\mathrm{Ag}$ nanoparticles additive in the polyurea coating. In both methods, the population of bacteria decreased considerably with the addition of $\mathrm{Ag}$ nanoparticles. The results showed that pure polyurea coating can affect the population of SRB slightly, but by adding Ag nanoparticles, the antibacterial effect of coating improves significantly.

\subsection{Electrochemical properties}

EIS investigations were conducted to study the effects of adding $\mathrm{Ag}$ nanoparticles on the electrochemical properties of the polyurea coating. The pure and mixed coatings were immersed in the culture medium with SRB for a week. Fig. 5 shows the Nyquist diagrams of both pure and mixed coatings after 1 day and 1 week as results of the EIS tests. The proposed equivalent circuit used to fit the experimental data is shown in Fig. 5 , where $R_{s}$ denotes the solution resistance, $R_{f}$ is the coating resistance, $R_{\mathrm{ct}}$ is the charge transfer resistance, and $\mathrm{Q}$ is the constant phase element (CPE). The term of $n$ is the CPE power which expresses the CPE impedance. For $\mathrm{n}=0.8$, the behavior of CPE reflects the non-ideal capacitance $(\mathrm{n}<1)$ (Härkönen et al., 2011).

The values of the electrochemical equivalent circuit elements are given in Table 2. The data reported in Table 2 shows the improvement of the corrosion properties of the polyurea coating with added Ag
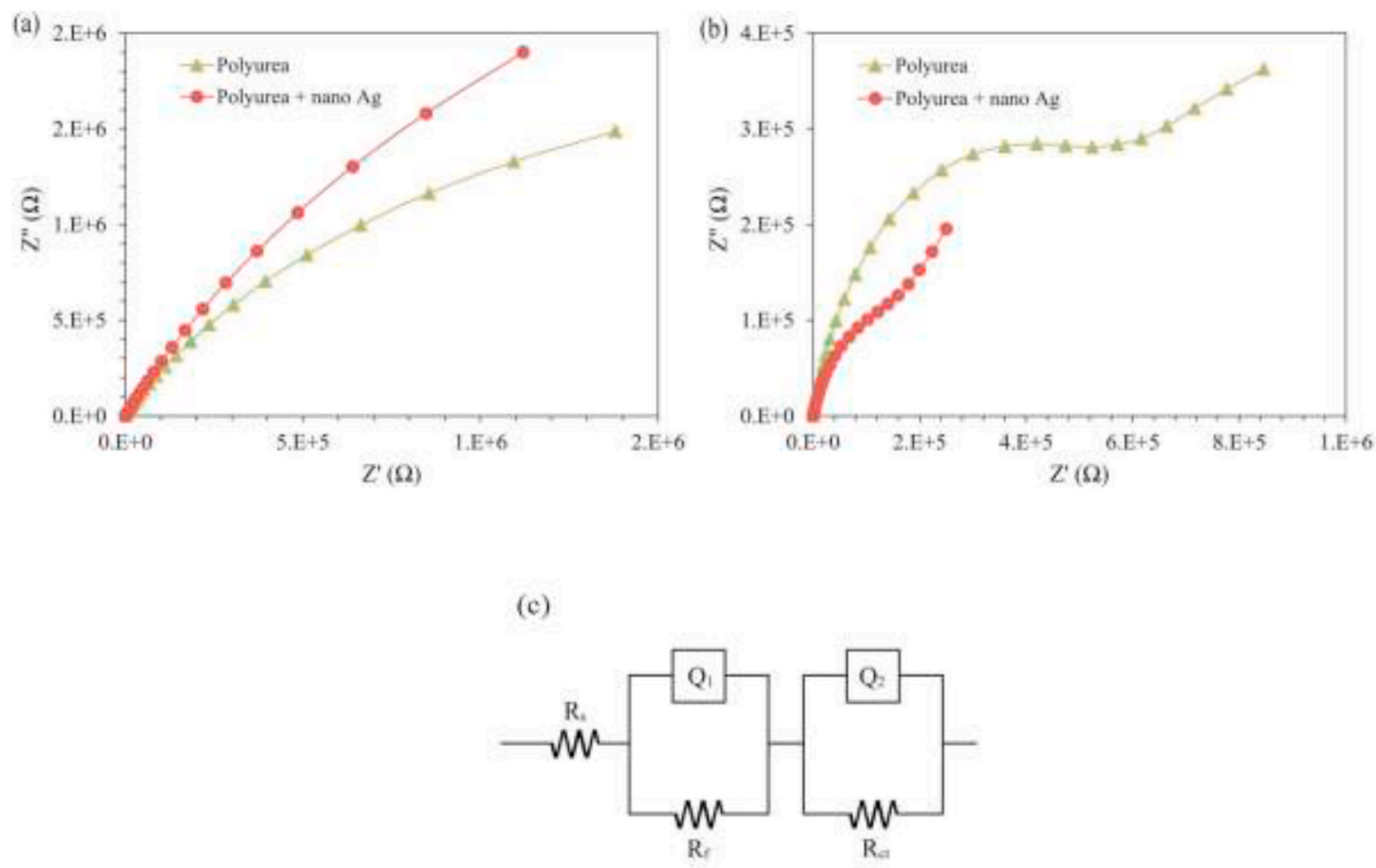

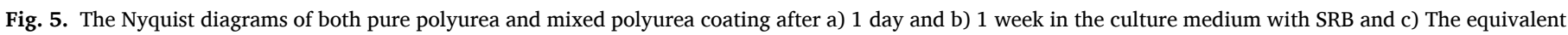
circuit proposed for the electrochemical impedance response.

Table 2

The values of electrochemical equivalent circuit elements as results of EIS for pure polyurea and mixed polyurea coating.

\begin{tabular}{|c|c|c|c|c|c|c|c|c|}
\hline Coating & Immersion Time & $\mathrm{R}_{\mathrm{S}}$ & $\mathrm{Q}_{1}$ & $\mathrm{n}$ & $\mathrm{R}_{\mathrm{f}}$ & $\mathrm{Q}_{2}$ & $\mathrm{n}$ & $\mathrm{R}_{\mathrm{ct}}$ \\
\hline \multirow[t]{2}{*}{ Polyurea } & 1 day & 212.8 & $2.37 \times 10^{-5}$ & 0.80 & $2.17 \times 10^{6}$ & $2.44 \times 10^{-5}$ & 0.80 & $9.28 \times 10^{6}$ \\
\hline & 1 week & 281.3 & $2.79 \times 10^{-4}$ & 0.80 & $1.68 \times 10^{5}$ & $6.47 \times 10^{-5}$ & 0.80 & $9.72 \times 10^{5}$ \\
\hline \multirow[t]{2}{*}{ Polyurea + nano Ag } & 1 day & 184.2 & $2.01 \times 10^{-5}$ & 0.77 & $4.39 \times 10^{6}$ & $3.36 \times 10^{-4}$ & 0.76 & $1.45 \times 10^{7}$ \\
\hline & 1 week & 238.9 & $9.38 \times 10^{-5}$ & 0.78 & $5.67 \times 10^{5}$ & $1.14 \times 10^{-5}$ & 0.84 & $1.07 \times 10^{6}$ \\
\hline
\end{tabular}


nanoparticles in both 1-day and 1-week EIS measurements.

The values reported in Table 2 for $\mathrm{R}_{\mathrm{f}}$ and $\mathrm{R}_{\mathrm{ct}}$ represent that adding $\mathrm{Ag}$ nanoparticles increased the coating resistance 2 times after 1 day and 3.3 times after 7 days. In accordance with the same results, the charge transfer resistance was increased 1.5 times and 1.1 times with the addition of Ag nanoparticles after 1 day and 7 days, respectively. In general, the protective properties of the polyurea coating were improved with the addition of $\mathrm{Ag}$ nanoparticles in the culture medium with SRB after 7 days. Microbiological and electrochemical studies of the effects of adding $\mathrm{Ag}$ nanoparticles to polyurea coating revealed that Ag affected the SRB activities, preventing the formation of SRB biofilms on the coating surface and also controlled the bacteria population. Moreover, adding Ag nanoparticles improved the corrosion behavior of the samples by increasing the $R_{f}$ and $R_{c t}$. The results indicated that the nanocomposite coating acted as an almost perfect capacitor and showed resistance against the penetration of corrosive species such as water, oxygen, and ions into the coating.

\section{Conclusion}

To investigate the effects of adding Ag nanoparticles to polyurea on the microbiological and corrosion properties of the final coating, the antibacterial effects of the nanocomposite coating and electrochemical properties of the coated samples were studied in media containing SRB, and the following conclusions were observed:

1. Ag nanoparticles prevented the formation of SRB biofilm on the surface of mixed polyurea coating in the medium containing SRB.

2. Blackening, the smell of hydrogen sulfide gas, and black sulfide sediments appeared after 7 days in the control sample, but no evidence was detected in the Ag nanoparticles-composited polyurea coating medium at the same time.

3. The MPN and CFU estimations clarified the antibacterial effects of the Ag nanoparticles additive in the polyurea coating by significantly reducing the SRB population.

4. By adding Ag nanoparticles to the polyurea coating, the protective properties of the final coating were improved considerably in SRBcontaining media.

\section{Credit author statement}

Dr. Sajjad Bordbar, Seyed Jafar Mousavi, Mouj Khaleghi: Experimental part, Dr. Majid Mahdavian and Rozhin Darabig: Characterization of data and analysis of experimental part, Prof. Hassan Karimi-Maleh, Mehmet Lütfi Yola, Mei Liu: Writing- Original draft preparation and revise of paper.

\section{Declaration of competing interest}

The authors declare that they have no known competing financial interests or personal relationships that could have appeared to influence the work reported in this paper.

\section{References}

Ahmadi, H., Hosseini, E., Cha-Umpong, W., Abdollahzadeh, M., Korayem, A.H., Razmjou, A., Chen, V., Asadnia, M., 2020. Incorporation of Natural Lithium-Ion Trappers into Graphene Oxide Nanosheets. Advanced Materials Technologies, p. 2000665.

Akça, A., Karaman, O., Karaman, C., 2021. Mechanistic insights into catalytic reduction of $\mathrm{N} 2 \mathrm{O}$ by $\mathrm{CO}$ over Cu-embedded graphene: a density functional theory perspective. ECS J. Solid State Sci. Technol. 10, 041003.

Al-Turaif, H.A., 2010. Effect of nano TiO2 particle size on mechanical properties of cured epoxy resin. Prog. Org. Coating 69 (3), 241-246.

AlAbbas, F.M., Bhola, R., Spear, J.R., Olson, D.L., Mishra, B., 2013. Electrochemical characterization of microbiologically influenced corrosion on linepipe steel exposed to facultative anaerobic Desulfovibrio sp. Int J Electrochem Sci 8, 859-871.

Alavi-Tabari, S.A., Khalilzadeh, M.A., Karimi-Maleh, H., 2018. Simultaneous determination of doxorubicin and dasatinib as two breast anticancer drugs uses an amplified sensor with ionic liquid and $\mathrm{ZnO}$ nanoparticle. J. Electroanal. Chem. 811, 84-88.

Arzaghi, H., Rahimi, B., Adel, B., Rahimi, G., Taherian, Z., Sanati, A.L., Dezfuli, A.S., 2021. Nanomaterials modulating stem cells behavior towards cardiovascular cell linage. Materials Advances 2, 2231-2262.

Bhola, S.M., Alabbas, F.M., Bhola, R., Spear, J.R., Mishra, B., Olson, D.L., Kakpovbia, A. E., 2014. Neem extract as an inhibitor for biocorrosion influenced by sulfate reducing bacteria: a preliminary investigation. Eng. Fail. Anal. 36, 92-103.

Bushnak, I.A., Labeed, F.H., Sear, R.P., Keddie, J.L., 2010. Adhesion of microorganisms to bovine submaxillary mucin coatings: effect of coating deposition conditions. Biofouling 26 (4), 387-397.

Cha-Umpong, W., Hosseini, E., Razmjou, A., Zakertabrizi, M., Korayem, A.H., Chen, V., 2019. New molecular understanding of hydrated ion trapping mechanism during thermally-driven desalination by pervaporation using GO membrane. J. Membr. Sci. 117687.

Cha-umpong, W., Li, Q., Razmjou, A., Chen, V., 2021. Concentrating brine for lithium recovery using GO composite pervaporation membranes. Desalination 500, 114894.

Chen, X., Mao, S.S., 2007. Titanium dioxide nanomaterials: synthesis, properties, modifications, and applications. Chem. Rev. 107 (7), 2891-2959.

Chen, M., Yang, L., Zhang, L., Han, Y., Lu, Z., Qin, G., Zhang, E., 2017. Effect of nano/ micro-Ag compound particles on the bio-corrosion, antibacterial properties and cell biocompatibility of Ti-Ag alloys. Mater. Sci. Eng. C 75, 906-917.

Dehhaghi, M., Tabatabaei, M., Aghbashlo, M., Panahi, H.K.S., Nizami, A.-S., 2019. A state-of-the-art review on the application of nanomaterials for enhancing biogas production. J. Environ. Manag. 251, 109597.

Elshawesh, F., Abusowa, K., Mahfud, H., Abderraheem, A., Eljweli, F., Zyada, K., 2008. Microbial-influenced corrosion (MIC) on an 18 in. API 5L X52 trunkline. J. Fail. Anal. Prev. 8 (1), 60-68.

Gayosso, M.H., Olivares, G.Z., Ordaz, N.R., Ramirez, C.J., Esquivel, R.G., Viveros, A.P., 2004. Microbial consortium influence upon steel corrosion rate, using polarisation resistance and electrochemical noise techniques. Electrochim. Acta 49 (25), 4295-4301.

Ghazy, E., Mahmoud, M., Asker, M., Mahmoud, M., Abo Elsoud, M., Abdel Sami, M., 2011. Cultivation and detection of sulfate reducing bacteria (SRB) in sea water. Journal of American Science 7 (2), 604-608.

Ghoreishi, S., Shabani-Nooshabadi, M., Behpour, M., Jafari, Y., 2012. Electrochemical synthesis of poly (o-anisidine) and its corrosion studies as a coating on aluminum alloy 3105. Prog. Org. Coating 74 (3), 502-510.

Härkönen, E., Diaz, B., Światowska, J., Maurice, V., Seyeux, A., Vehkamäki, M., Sajavaara, T., Fenker, M., Marcus, P., Ritala, M., 2011. Corrosion protection of steel with oxide nanolaminates grown by atomic layer deposition. J. Electrochem. Soc. 158 (11), C369.

Holtz, R.D., Lima, B.A., Souza Filho, A.G., Brocchi, M., Alves, O.L., 2012. Nanostructured silver vanadate as a promising antibacterial additive to water-based paints. Nanomed. Nanotechnol. Biol. Med. 8 (6), 935-940.

Hosseinzadeh-Bandbafha, H., Khalife, E., Tabatabaei, M., Aghbashlo, M., Khanali, M., Mohammadi, P., Shojaei, T.R., Soltanian, S., 2019. Effects of aqueous carbon nanoparticles as a novel nanoadditive in water-emulsified diesel/biodiesel blends on performance and emissions parameters of a diesel engine. Energy Convers. Manag. 196, 1153-1166.

Huang, T.-C., Su, Y.-A., Yeh, T.-C., Huang, H.-Y., Wu, C.-P., Huang, K.-Y., Chou, Y.-C., Yeh, J.-M., Wei, Y., 2011. Advanced anticorrosive coatings prepared from electroactive epoxy-SiO2 hybrid nanocomposite materials. Electrochim. Acta 56 (17), 6142-6149.

Jafari, Y., Shabani-Nooshabadi, M., Ghoreishi, S.M., 2014. Electropolymerized coatings of poly (o-anisidine) and poly (o-anisidine)-TiO2 nanocomposite on aluminum alloy 3004 by using the galvanostatic method and their corrosion protection performance. Polym. Adv. Technol. 25 (3), 279-287.

Javaherdashti, R., 2011. Impact of sulphate-reducing bacteria on the performance of engineering materials. Appl. Microbiol. Biotechnol. 91 (6), 1507-1517.

Kaduková, J., Škvareková, E., Mikloš, V., Marcinčáková, R., 2014. Assessment of microbially influenced corrosion risk in Slovak pipeline transmission network. J. Fail. Anal. Prev. 14 (2), 191-196.

Kahlmeter, G., Brown, D., Goldstein, F., MacGowan, A., Mouton, J., Odenholt, I., Rodloff, A., Soussy, C.J., Steinbakk, M., Soriano, F., 2006. European Committee on Antimicrobial Susceptibility Testing (EUCAST) Technical Notes on Antimicrobial Susceptibility Testing. Wiley Online Library.

Karaman, C., Aktaș, Z., Bayram, E., Karaman, O., Kızıl, C., 2020. Correlation between the molecular structure of reducing agent and $\mathrm{pH}$ of graphene oxide dispersion on the formation of 3D-graphene networks. ECS Journal of Solid State Science and Technology 9 (7), 071003.

Karimi, F., Zakariae, N., Esmaeili, R., Alizadeh, M., Tamadon, A.-M., 2020. Carbon nanotubes for amplification of electrochemical signal in drug and food analysis; A mini review. Current Biochemical Engineering 6 (2), 114-119.

Karimi-Maleh, H., Sanati, A.L., Gupta, V.K., Yoosefian, M., Asif, M., Bahari, A., 2014. A voltammetric biosensor based on ionic liquid/NiO nanoparticle modified carbon paste electrode for the determination of nicotinamide adenine dinucleotide (NADH). Sensor. Actuator. B Chem. 204, 647-654.

Karimi-Maleh, H., Kumar, B.G., Rajendran, S., Qin, J., Vadivel, S., Durgalakshmi, D., Gracia, F., Soto-Moscoso, M., Orooji, Y., Karimi, F., 2020. Tuning of metal oxides photocatalytic performance using Ag nanoparticles integration. J. Mol. Liq. 314, 113588.

Karimi-Maleh, H., Yola, M.L., Atar, N., Orooji, Y., Karimi, F., Kumar, P.S., Rouhi, J, Baghayeri, M., 2021a. A novel detection method for organophosphorus insecticide fenamiphos: molecularly imprinted electrochemical sensor based on core-shell Co3O4@ MOF-74 nanocomposite. J. Colloid Interface Sci. 592, 174-185. 
Karimi-Maleh, H., Ranjbari, S., Tanhaei, B., Ayati, A., Orooji, Y., Alizadeh, M., Karimi, F., Salmanpour, S., Rouhi, J., Sillanpää, M., 2021b. Novel 1-butyl-3-methylimidazolium bromide impregnated chitosan hydrogel beads nanostructure as an efficient nanobioadsorbent for cationic dye removal: kinetic study. Environ. Res. 195, 110809.

Karimi-Maleh, H., Alizadeh, M., Orooji, Y., Karimi, F., Baghayeri, M., Rouhi, J., Tajik, S., Beitollahi, H., Agarwal, S., Gupta, V.K., 2021c. Guanine-based DNA biosensor amplified with Pt/SWCNTs nanocomposite as analytical tool for nanomolar determination of daunorubicin as an anticancer drug: a docking/experimental investigation. Ind. Eng. Chem. Res. 60 (2), 816-823.

Khalife, E., Tabatabaei, M., Najafi, B., Mirsalim, S.M., Gharehghani, A., Mohammadi, P., Aghbashlo, M., Ghaffari, A., Khounani, Z., Shojaei, T.R., 2017. A novel emulsion fuel containing aqueous nano cerium oxide additive in diesel-biodiesel blends to improve diesel engines performance and reduce exhaust emissions: Part I-Experimental analysis. Fuel 207, 741-750.

Khodadadi, A., Faghih-Mirzaei, E., Karimi-Maleh, H., Abbaspourrad, A., Agarwal, S., Gupta, V.K., 2019. A new epirubicin biosensor based on amplifying DNA interactions with polypyrrole and nitrogen-doped reduced graphene: experimental and docking theoretical investigations. Sensor. Actuator. B Chem. 284, 568-574.

Klančnik, A., Piskernik, S., Jeršek, B., Možina, S.S., 2010. Evaluation of diffusion and dilution methods to determine the antibacterial activity of plant extracts. J. Microbiol. Methods 81 (2), 121-126.

Kumar, P.S., Vincent, C., Kirthika, K., Kumar, K.S., 2010. Kinetics and equilibrium studies of $\mathrm{Pb} 2+$ in removal from aqueous solutions by use of nano-silversol-coated activated carbon. Braz. J. Chem. Eng. 27 (2), 339-346.

Kumar, P.S., Varjani, S.J., Suganya, S., 2018. Treatment of dye wastewater using an ultrasonic aided nanoparticle stacked activated carbon: kinetic and isotherm modelling. Bioresour. Technol. 250, 716-722.

Liu, X., Gan, K., Liu, H., Song, X., Chen, T., Liu, C., 2017. Antibacterial properties of nano-silver coated PEEK prepared through magnetron sputtering. Dent. Mater. 33 (9), e348-e360.

Ma, Y., 2019. Seed coating with beneficial microorganisms for precision agriculture. Biotechnol. Adv. 37 (7), 107423.

Mallon, P., 2003. Application to polymers. Principles and application of positron \& positronium chemistry 1 .

Manninen, N., Carvalho, I., Henriques, M., Cavaleiro, A., Carvalho, S., 2016. Antibacterial Ag/aC nanocomposite coatings: the influence of nano-galvanic aC and Ag couples on Ag ionization rates. Appl. Surf. Sci. 377, 283-291.

Mansfeld, F., 1995. Use of electrochemical impedance spectroscopy for the study of corrosion protection by polymer coatings. J. Appl. Electrochem. 25 (3), 187-202.

Mirmohseni, A., Zavareh, S., 2010. Preparation and characterization of an epoxy nanocomposite toughened by a combination of thermoplastic, layered and particulate nano-fillers. Mater. Des. 31 (6), 2699-2706.

Mirzajanzadeh, M., Tabatabaei, M., Ardjmand, M., Rashidi, A., Ghobadian, B., Barkhi, M., Pazouki, M., 2015. A novel soluble nano-catalysts in diesel-biodiesel fuel blends to improve diesel engines performance and reduce exhaust emissions. Fuel 139, 374-382.
Mohammad, M., Lisiecki, M., Liang, K., Razmjou, A., Chen, V., 2020. Metal-Phenolic network and metal-organic framework composite membrane for lithium ion extraction. Applied Materials Today 21, 100884.

Neeraj, G., Krishnan, S., Kumar, P.S., Shriaishvarya, K.R., Kumar, V.V., 2016. Performance study on sequestration of copper ions from contaminated water using newly synthesized high effective chitosan coated magnetic nanoparticles. J. Mol. Liq. 214, 335-346.

Özcan, N., Karaman, C., Atar, N., Karaman, O., Yola, M.L., 2020. A novel molecularly imprinting biosensor including graphene quantum dots/multi-walled carbon nanotubes composite for interleukin-6 detection and electrochemical biosensor validation. ECS Journal of Solid State Science and Technology 9 (12), 121010.

Pour, Z.S., Ghaemy, M., 2014. Thermo-mechanical behaviors of epoxy resins reinforced with silane-epoxide functionalized $\alpha$-Fe2O3 nanoparticles. Prog. Org. Coating 77 (8), 1316-1324.

Razmjou, A., Asadnia, M., Hosseini, E., Korayem, A.H., Chen, V., 2019. Design principles of ion selective nanostructured membranes for the extraction of lithium ions. Nat Commun. 10 (1), 1-15.

Saravanan, A., Kumar, P.S., Devi, G.K., Arumugam, T., 2016. Synthesis and characterization of metallic nanoparticles impregnated onto activated carbon using leaf extract of Mukia maderasapatna: evaluation of antimicrobial activities. Microb. Pathog. 97, 198-203.

Saravanan, A., Kumar, P.S., Karishma, S., Vo, D.-V.N., Jeevanantham, S., Yaashikaa, P., George, C.S., 2020. A review on biosynthesis of metal nanoparticles and its environmental applications. Chemosphere 128580.

Sekhavat Pour, Z., Ghaemy, M., 2014. Fabrication and characterization of superparamagnetic nanocomposites based on epoxy resin and surface-modified $\gamma$-FeO by epoxide functionalization. J. Mater. Sci. 49 (12).

Shabani-Nooshabadi, M., Ghoreishi, S.M., Jafari, Y., Kashanizadeh, N., 2014. Electrodeposition of polyaniline-montmorrilonite nanocomposite coatings on 316L stainless steel for corrosion prevention. J. Polym. Res. 21 (4), 1-10.

Shabani-Nooshabadi, M., Ghoreishi, S., Eghbali-Bidgoli, H., Jafari, Y., 2015. Direct electrosynthesis of polyaniline-Fe2O3 nanocomposite coating on aluminum alloy 5052 and its corrosion protection performance. Journal of Nanostructures 5 (4), 423-435.

Sharma, P., 2014. Microbiological-influenced corrosion failure of a heat exchanger tube of a fertilizer plant. J. Fail. Anal. Prev. 14 (3), 314-317.

Shi, H., Liu, F., Yang, L., Han, E., 2008. Characterization of protective performance of epoxy reinforced with nanometer-sized TiO2 and SiO2. Prog. Org. Coating 62 (4), 359-368.

Tan, C., Blackwood, D., 2003. Corrosion protection by multilayered conducting polymer coatings. Corrosion Sci. 45 (3), 545-557.

Zhang, X., Zhu, M., Wang, W., Yu, D., 2018. Silver/waterborne polyurethane-acrylate's antibacterial coating on cotton fabric based on click reaction via ultraviolet radiation. Prog. Org. Coating 120, 10-18. 